\title{
Ground Motion Simulation of Hypothetical Earthquakes in the Upper North I sland of New Zealand
}

\author{
D Dempsey¹, JD Eccles ${ }^{1}$, J Huang², S J eong ${ }^{3}$, E Nicolin¹, A Stolte², \\ L Wotherspoon $^{1}$, and BA Bradley ${ }^{2}$ \\ IUniv. Auckland 2 Univ. Canterbury ${ }^{3}$ Changwon Natl. Univ., South Korea
}

The upper North I sland of New Zealand has large concentrations of population and infrastructure that make it vulnerable to earthquakes on the Kerepehi and Wairoa North faults. Using a physicsbased simulator, we modelled ground motions for $M_{w} 7.3$ and $M_{w} 6.6$ characteristic earthquakes on these structures. We considered the effects of low-velocity basins beneath the Hauraki Rift and the city of Hamilton that can amplify ground shaking. For a Kerepehi Fault earthquake, long period shaking was amplified a by factor of two to three in Hamilton and towns near the Firth of Thames. Severe to violent, long duration shaking would occur close to the source with the potential to trigger liquefaction that could damage flood defence networks and farmland in the Hauraki Plains. Auckland, Hamilton and Tauranga would experience moderate to very strong shaking. I mpacts in Auckland are larger for a Wairoa North Fault earthquake, which could generate peak ground accelerations of $0.5 \mathrm{~g}$ at reservoir dams in the Hūnua Ranges, $0.2 \mathrm{~g}$ at the international airport, and 0.1 to $0.2 \mathrm{~g}$ at the CBD and port. Road, rail and transmission networks are vulnerable to disruption where they converge at infrastructure hotspots $10 \mathrm{~km}$ from the fault in South Auckland.

\section{Simulation methodology}

Ground motion simulations were performed using the Graves \& Pitarka (2016) hybrid method, with deterministic low-frequency simulation below $1 \mathrm{~Hz}$ (using a $100 \mathrm{~m}$ grid spacing) and stochastic high-frequency simulation above.

We used the NZ Velocity Model modified to include Hauraki Rift and Hamilton/Waikato basins. Basin surfaces were developed from geologic maps, topography and inspection of geophysical data (Fig. 1). Basin velocity properties were defined as linearly increasing functions of depth, approximately 2 to 3 times smaller than basement velocities at the interface. A spatial $V_{s 3}$ correction was applied using the map of Foster et al. (2019)

Validation against five $M \leq 4.6$ regiona earthquakes indicated no major biases in the simulated intensity measures (IMs)

Hypothetical earthquake sources were approximated as planes fitted to mapped faults (Fig. 1), dipping $70^{\circ} \mathrm{SW}$ and assigned a characteristic magnitude using the Leonard (2010) scaling relation. Eight stochastic slip realisations were simulated for each source, and average IMs computed.

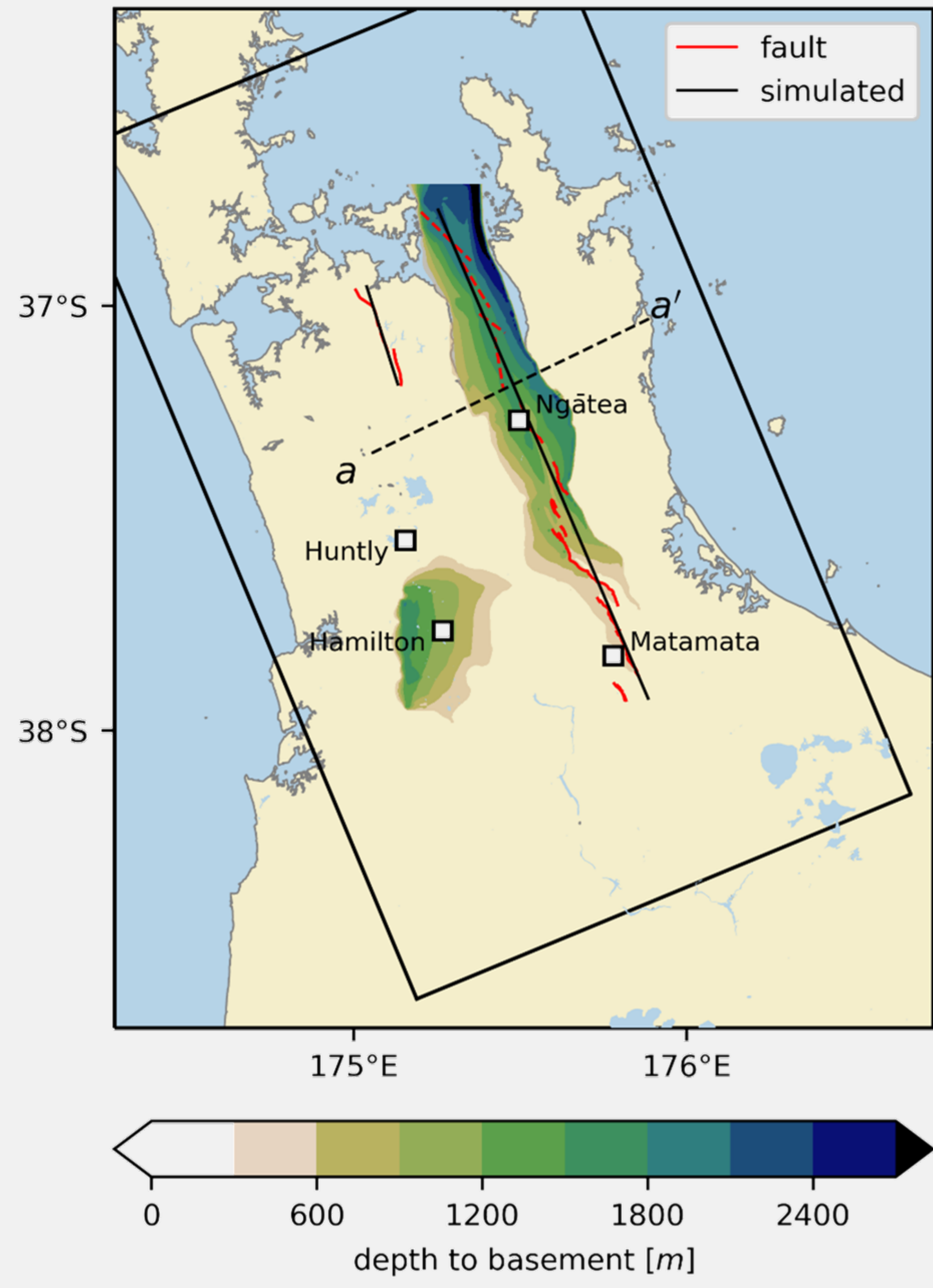

Figure 1: Location and depth of Hauraki Rift and Hamilton/Waikato basins in the computational domain (black box). Active fauts (red) and approximated sources (black

\section{I mpacts on Auckland infrastructure}

MMI shaking across Auckland for both Kerepehi and Wairoa North fault earthquakes varied between 5 and 6 in the north and west, and between 6 and 7 in the south. Convergence of road, rail and transmission networks between Takanini and Drury is a particular hotspot, with damage here potentially cutting Auckland city and the Northland region off from the rest of the country. A detailed infrastructure impact assessment by the Auckland Engineering Lifelines Group (AELG, 2014) is likely to be a good guide for other impacts and recovery times.
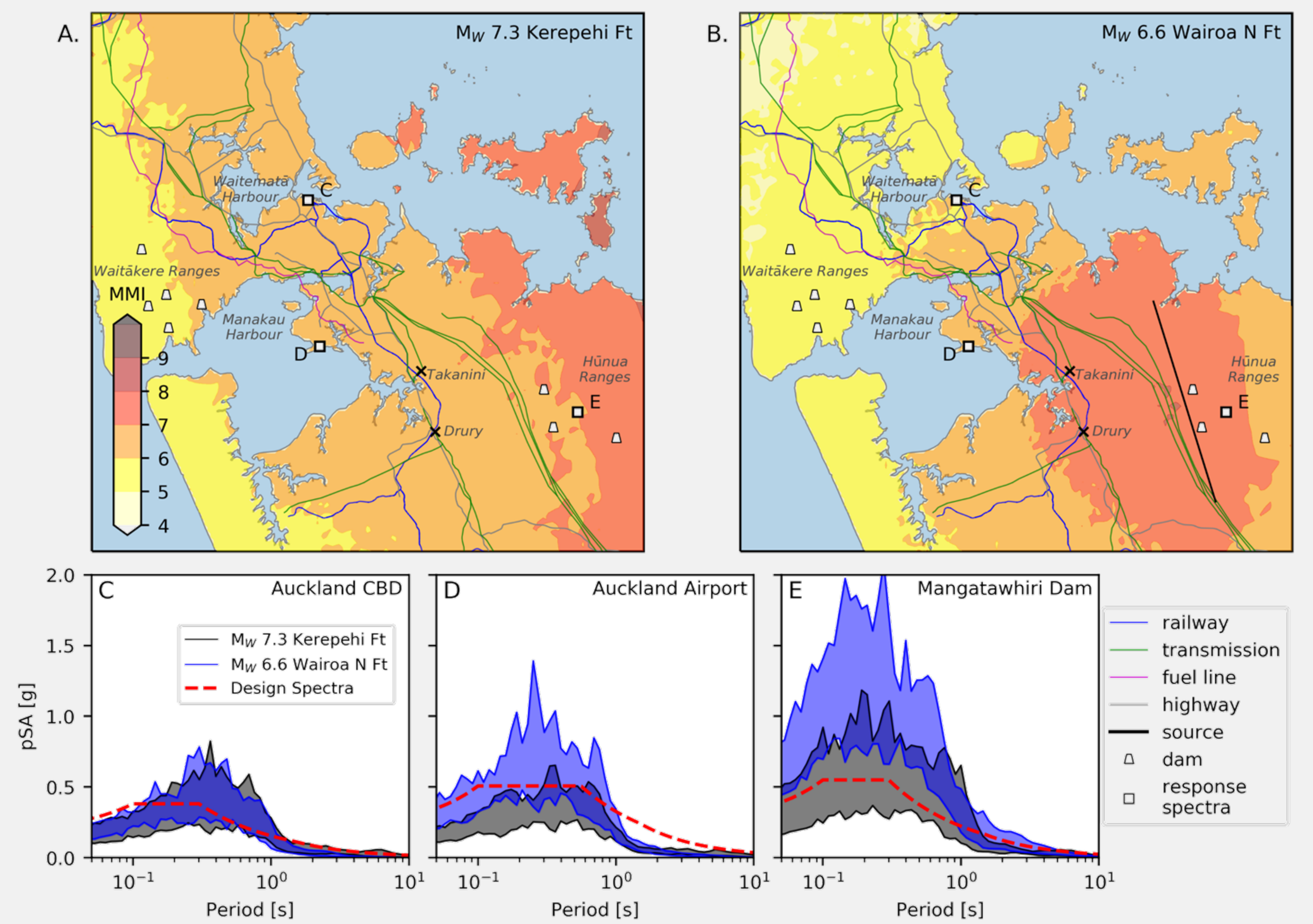

Figure 3: Simulated MMI contours from (A) Kerepehi Fault and (B) Wairoa North Fault earthquakes in the context of regional Auckland infrastructure. Simulated spectra $( \pm 2 \sigma)$ at (C) the CBD/Port, (D) airport, and (E) a Hūnua ranges dam compared with design spectra.

Simulated spectral accelerations were inspected at three sites. For the $M_{w} 6.6$ Wairoa $\mathrm{N} \mathrm{Ft}$ earthquake, shaking had the potential to exceed design spectra at the CBD (shallow soils, 500 year return), airport (deep soils, 1000 year return) and Hūnua Ranges reservoirs (rock, 2500 year return for a safety evaluation earthquake). Dams that experienced similar shaking following the $2010 \mathrm{M}_{\mathrm{w}} 8.8$ Maule, Chile earthquake performed well with only minor slope failures, however land-sliding into the reservoir could pose a problem.

\section{Findings and future directions}

The earthquake simulations here are intended as indicative scenarios to assist with disaster planning. Impacts from other earthquakes, for example an $M_{w} 6.6$ earthquake on the Awaiti strand of the Kerepehi Fault near Thames, could be abstracted from the simulated IMs. Other downstream uses of these simulations include boundary condition inputs to specific structural models (e.g., response of the Mangatawhiri Dam), liquefaction investigation of Hauraki Plains soils, or as input for landslide exposure models.

\section{Basin amplification effects}

For the $\mathrm{M}_{\mathrm{w}} 7.3$ Kerepehi Fault earthquake, simulated MMI (Fig. 2A) varies between 8 and 9 close to the source, and between 6 and 7 at Hamilton, Tauranga and Auckland. Low velocities in the Hamilton/Waikato and Hauraki Rift basins amplify shaking intensity and duration, particularly at frequencies larger than 1s (Fig. 2B). Significant duration (Ds595, not shown) varies by up to $20 \mathrm{~s}$ depending on hypocentre location and site orientation.
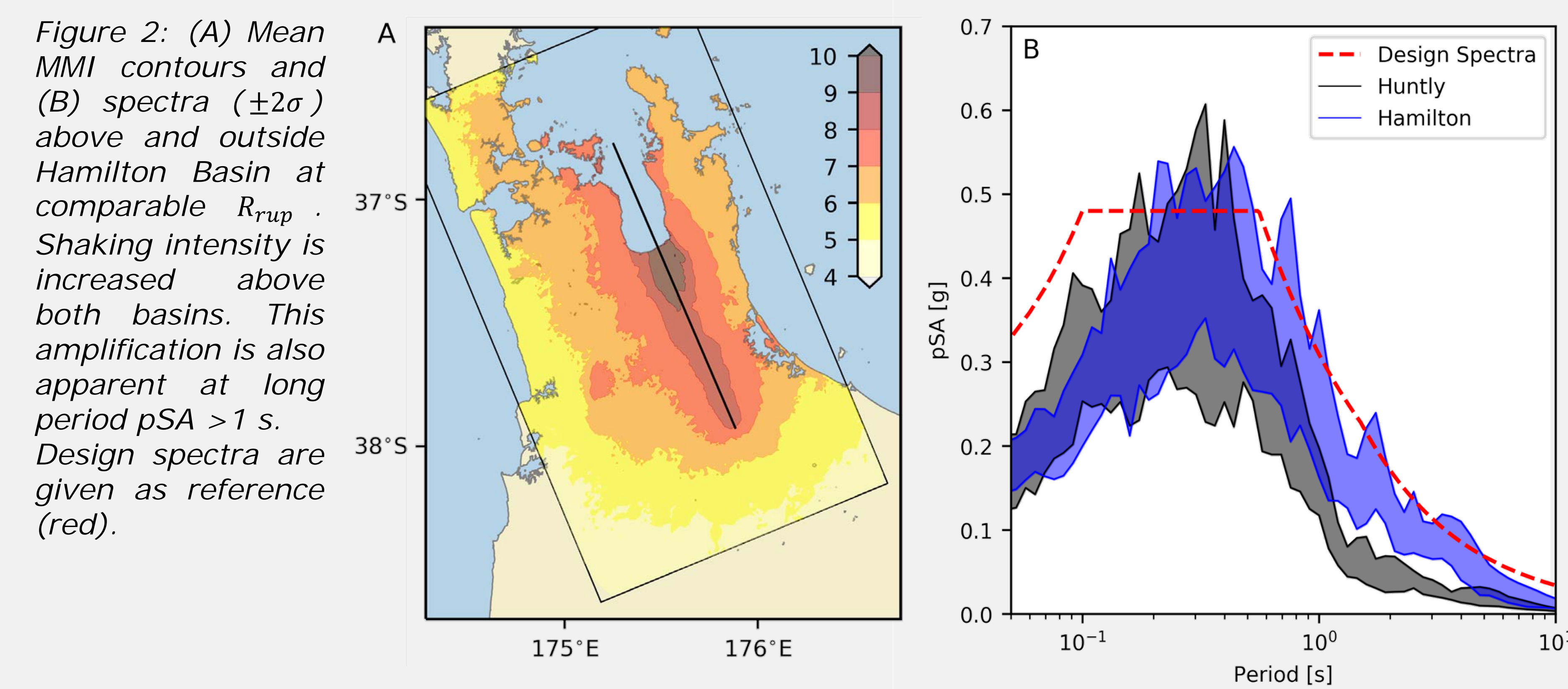

\section{I mpacts on Waikato flood defence network}

Liquefaction, spreading stop banks and leave regions exposed to flooding hazards. In the low-lying Hauraki Plains, extensive flood defence networks along the Piako and Waihou rivers would experience long, intense shaking (CAV > $2 \mathrm{~g} \mathrm{~s})$ from a Kerepehi Ft earthquake, amplified by the deep basin. Soft peat or sandy/silty deposits could soften or liquefy.

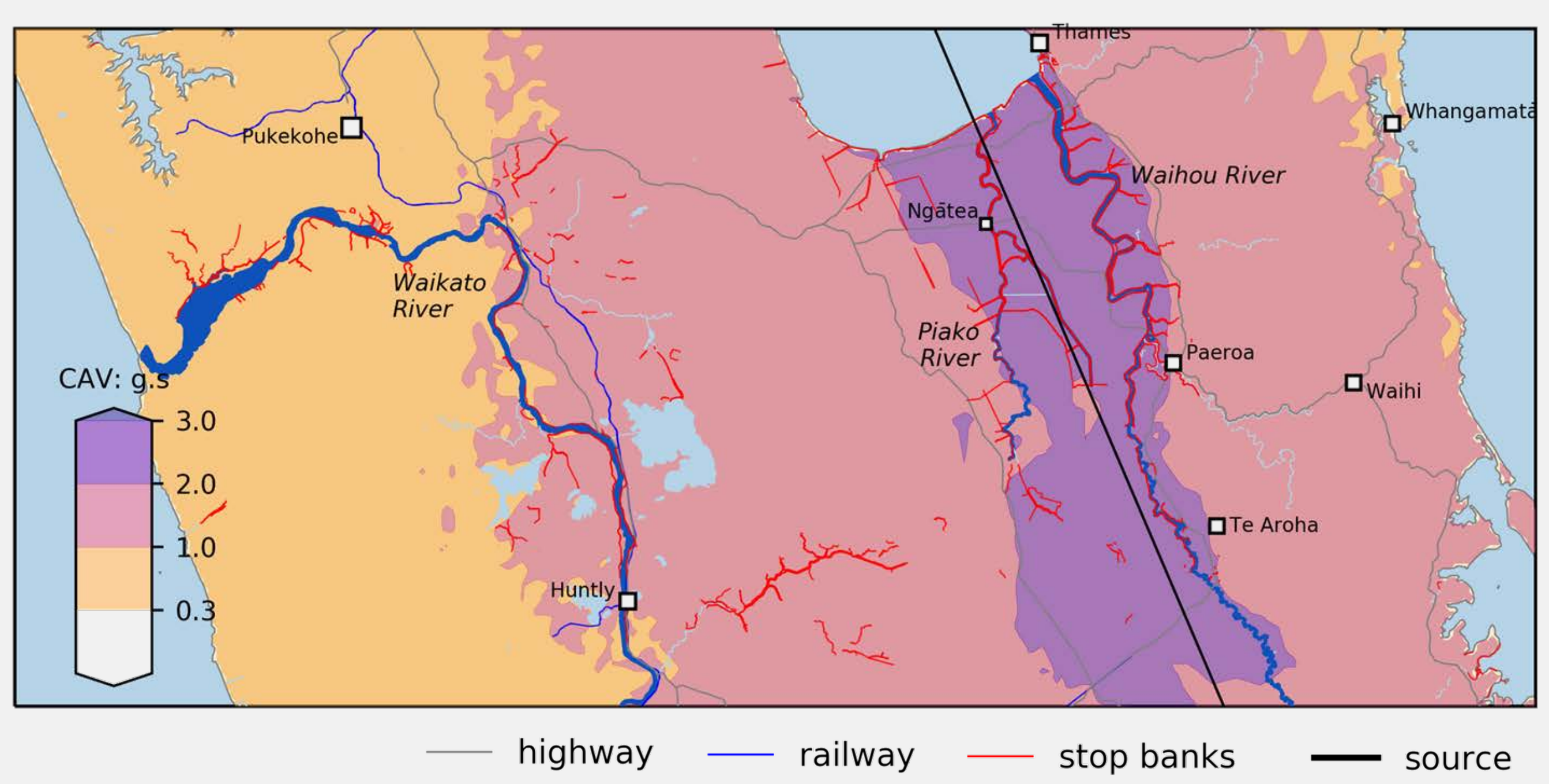

Figure 4: Simulated cumulative absolute velocity (CAV) in the context of the Waikato flood defence network. The low-lying Hauraki Plains is particularly exposed (CAV > $2 \mathrm{~g}$ s) to potential liquefaction. or cracking can damage 